\title{
A Análise da Implementação da Estratégia B2C em um Canal B2B: um estudo de caso da Coloplast
}

\author{
Lucas Stellin Miranda (USP) - brlm@coloplast.com \\ Leonel Gois Lima Oliveira (UNICHRISTUS) - leonelgois@gmail.com
}

\begin{abstract}
RESUMO: Uma vez estabelecidos, os conceitos, as categorias e as estratégias se tornam difíceis de serem flexibilizados ou combinados. Essa inflexibilidade na mescla de estratégias pode trazer uma limitação na eficiência. Este estudo propõe estudar uma estratégia híbrida, de uma empresa dinamarquesa de dispositivos médicos, que tem em sua unidade de negócios estudada o Business to Business como modelo de negócio. A estratégia insere um foco no consumidor final, Business to Consumer, dentro da estratégia B2B. O planejamento e implementação desta estratégia em um projeto piloto é estudado, usando os 4P's do marketing mix como moldura. Analisa-se, também, o resultado desta nova estratégia, usando como mensurável metas e premissas de crescimento definidas no início do projeto. A metodologia usada foi a descrição do caso, proposições teóricas e análises matemáticas. Os objetivos foram atingidos e resultados satisfatórios, porém, limitações como tempo transcorrido e amostragem reduzida não nos deixam afirmar que modelo proposto é uma estratégia eficiente.
\end{abstract}

PALAVRAS-CHAVE: Mix de Marketing; Business to Consumer; Business to Business.

\section{The Analysis of the Implementation of the B2C Strategy on a B2B Channel: a Coloplast Case Study}

\begin{abstract}
Once established, the concepts, the categories and the strategies become hard to flexibilize or combine. This inflexibility in the mix of strategies can bring limitation in efficiency. This study proposes the study of a hybrid strategy, from a Danish medical devices company, that has the Business to Business as a business model in this business unit. The strategy inserts a focus on the final consumer, Business to Consumer, inside a B2B business model. The planning and implementation of this strategy in a pilot project is studied, using the 4Ps of marketing mix as framework. The results of this strategy are analyzed, using as measurable targets and assumptions that were established at the beginning of the project. The methodology used was case description, theoretical propositions and mathematical analysis. The objectives were accomplished and satisfactory, but limitations such as time and reduced sample don't allow us to confirm the proposed model as an efficient strategy.
\end{abstract}

KEYWORDS: Marketing Mix; Business to Consumer; Business to Business.

\begin{tabular}{c} 
R. Desembargador Ellis Hermydio Figueira, 783, Bloco A, sl. 304, Aterrado. \\
27213-145 - Volta Redonda, RJ - Brasil \\
www.uff.br \\
Wluminersidade \\
\hline
\end{tabular}

Copyright (C) 2018 RASI. Todos os direitos, até mesmo de tradução, são reservados. É permitido citar parte de artigos sem autorização prévia, desde que seja identificada a fonte 


\section{A Análise da Implementação da Estratégia B2C em um Canal B2B: um estudo de caso da Coloplast}

\section{Introdução}

A influência do ambiente na dinâmica do mercado é ratificada por mudanças no cenário dos negócios. $\mathrm{O}$ aumento exponencial da competitividade pode ser uma consequência das constantes adaptações do macroambiente que, além de serem incontroláveis, estão cada vez mais imprevisíveis. Essa mudança ocorre, principalmente, pela instabilidade do ambiente político-econômico, desenvolvimento acelerado do tecnológico e pela mudança do ambiente sociocultural. No panorama brasileiro, a importância da dinamicidade e as rápidas respostas às mudanças ambientais são fatores ainda mais preponderantes devido ao cenário de disfunção política e ao retorno da inflação rampante (The Economist, 2016).

Num mercado de extrema concorrência, para crescer e sobreviver, são necessários esforços e direcionamento por parte das organizações para criar uma vantagem competitiva. Esta cadeia é elencada por Dickson, Farris e Verbeke (2001) que defendem um fluxo de influência, onde o ambiente induz a estratégia, que por sua vez conduz a um posicionamento de vantagem competitiva. A obtenção da vantagem competitiva ocorre, segundo Porter (1986), por meio da adoção de táticas específicas para enfrentar as cinco forças competitivas estabelecidas pelo próprio autor. Estas táticas foram aglutinadas por Porter (1986) em três estratégicas competitivas genéricas: liderança no custo total, diferenciação e enfoque. Portanto, verifica-se a necessidade de uma maior atenção ao modelo de negócio, permitindo identificar o melhor funcionamento dos canais de distribuição e os aspectos de diferenciação que podem agregar mais valor ao negócio (Osterwalder, Pigneur, \& Clark, 2010).

A estratégia de diferenciação defende o alcance da vantagem por meio de oferta de produtos e serviços que tenham a qualidade desejada pelos consumidores, mas que também, possuam características diferentes dos produtos já ofertados pela concorrência. Em um mercado tão dinâmico e que exige sempre inovação, a diferenciação não pode limitar-se somente às características de produtos e serviços. Gummesson e Polese (2009) destacam a dificuldade na quebra de definições, categorias e conceitos, uma vez que esses são estabelecidos. Demonstram, ainda, como as ciências ocidentais reducionistas estão repletas por extremos e opostos: é sempre um ou outro, produtos ou serviços, Business to Business (B2B) ou Business to Consumer (B2C). Por outro lado, as ciências orientais quantitativas defendem uma visão holística, onde todas as partes estão interligadas e fazem parte de um sistema único. Ressalta-se a necessidade de mais conhecimentos sobre o B2B pela baixa quantidade de estudos publicados no Brasil no período na década compreendida de 1998 a 2007 conforme apontado por Lacerda e Mendonça (2010).

Objetivando a diferenciação, é válido adotar este conceito de adição e complementariedade, pensar em estratégias, canais, e soluções híbridas. Isso é confirmado por Kotler e Keller (2006) quando apontam a descentralização do foco e atendimento por produto e pelas divisões para foco em segmentação de clientes como uma das principais mudanças na administração de Marketing.

Nesse sentido, surge o questionamento: como ocorre o processo de integração da estratégia de canal do $B 2 C$, por parte de uma empresa, multinacional dinamarquesa de dispositivos médicos, predominantemente da estratégia de canal do $B 2 B$ ? É importante destacar que não existe uma migração de estratégia, de $B 2 B$ para $B 2 C$, e sim uma incorporação do foco da estratégia $B 2 C$ dentro do canal $B 2 B$. O objetivo do artigo consiste em 
analisar o modelo de negócios por meio da implementação de uma estratégia que foca no consumidor final em modelo já existente de $B 2 B$, a partir do estudo de caso na empresa Coloplast S.A.

$\mathrm{O}$ presente trabalho assume relevância em dois âmbitos. $\mathrm{Na}$ área acadêmica, sua importância reside no desenvolvimento de conteúdos que pretendem consolidar a possibilidade de coexistência entre os diferentes modelos. Ademais, é necessário o desenvolvimento de estudos que abranjam essa complexidade e, ao mesmo tempo, aprofundem tópicos de ordem estratégica para futuras pesquisas.

Em particular, a empresa aqui analisada já foi estudo de caso de pesquisas que abordaram o marketing de relacionamento e comunidades on-line (Andersen, 2005), design de engenharia (Onarheim, 2012), estratégias de operações (Nielsen-Englyst, 2003), e diferentes aspectos da área médica (Dhabuwala, C., Sheth, S., \& Zamzow, B., 2011). Entretanto, esse é o primeiro trabalho que se propõe a analisar o gap e as possibilidades da complementariedade de estratégias $B 2 C$ e $B 2 B$ no seu contexto, incluindo especificidades do cenário brasileiro e internacional. Tal abordagem poderá funcionar, ainda, como base para estudos de caso de outras empresas e/ou com diferentes focos teóricos.

No âmbito corporativo, será importante para validar a integração de uma abordagem B2C para a formatação de uma estratégia híbrida e comprovar o seu uso como um meio de diferenciação e/ou adaptação ao mercado. Atualmente, essa prática ainda é incipiente devido à mentalidade, muitas vezes binária, das empresas e à dificuldade de incorporar diferentes estratégias sem eliminar pilares essenciais (de ordem financeira, logística, etc.) ao seu funcionamento e competitividade.

\section{Mix Marketing e Estratégia de Canal}

O Mix de Marketing é conhecido também como composto mercadológico ou composto de marketing. É definido, de maneira objetiva, por Kotler (1998) como o conjunto de ferramentas usadas pela empresa para atingir seus objetivos de marketing em um mercado alvo. Já Bennett (1997) alega que o conceito delineia o curso de ação para a organização, usando variáveis controláveis em um ambiente onde muitos fatores são incontroláveis. Em outras palavras, o autor descreve o mix como uma maneira de traduzir o plano de marketing em prática.

Van Waterschoot e Van den Bulte (1992) definem formalmente o conceito de mix de marketing como o conjunto de elementos (ou instrumentos), impactantes na demanda, que podem ser combinados em um programa de marketing usado por uma empresa (ou qualquer organização) para atingir um certo nível ou tipo de resposta de seu público alvo. De uma maneira semelhante, McCarthy e Perreault (2002) explicam o mix de marketing como as variáveis controláveis que a empresa reúne para satisfazer seu público alvo e descreve um marketing mix típico como um produto, oferecido a um certo preço, com uma promoção para falar à potenciais consumidores sobre ele e uma forma de chegar ao local do consumidor.

Palmer (2004) afirma que o Marketing Mix não é uma teoria científica, mas apenas uma estrutura conceitual que identifica as principais decisões que os gestores de marketing fazem, adaptando a oferta para atender as necessidades dos consumidores. É importante destacar que, conforme afirmam Baker e Saren (2010), nem todos os instrumentos de marketing são também instrumentos do mix de marketing.

Goi (2009) destaca a importância da ferramenta para definir o papel do gestor de marketing e ajudar na alocação e gestão dos recursos disponíveis dentro e fora da moldura do Mix. Outra função para as ferramentas do Marketing Mix, elencada por Palmer (2004), é o 
suporte para desenvolver planos. Esses podem ser estratégias de longo prazo ou programas táticos de curto prazo. McCarthy e Perreault (2002) colocam o mix de marketing ao lado do mercado alvo como as duas partes da estratégia de marketing

O Mix de Marketing foi, primeiramente introduzido, segundo Van Waterschoot e Van den Bulte (1992), por Neil Borden, em seu discurso presidencial da American Marketing Association (AMA) em 1953. Segundo o próprio Borden (1984) a inspiração para o nome veio do artigo The Management of Marketing Costs, de 1948, onde o autor, James Culliton, descreve o executivo de negócios como "um decisor, um artista. Um misturador de ingredientes que as vezes segue a receita preparada por outros, as vezes prepara a sua própria receita[...]". Borden (1984) afirma ainda que gostou da ideia de chamar o executivo de marketing de "misturador de ingredientes", que está constantemente envolvido em criar uma mistura (mix) de procedimentos e políticas de marketing em seu esforço para produzir uma empresa rentável. Então, se o gestor é um misturador de ingredientes, ou "mixer of ingredients", do inglês, o que ele criou foi um "marketing mix".

A partir da percepção da existência do Mix de Marketing, formado por um composto variado de procedimento e políticas, Borden (1984) viu como próximo passo lógico a criação de um conceito, que deveria compreender não só essa variedade, mas também as forças de mercado que levam os gestores a produzir e adotar este composto.

Vários autores desenvolveram classificações e esquemas a partir da ideia de Borden, como Howard em 1957, McCarthy (1960), Lazer e Kelly em 1962, Frey em 1971, Lazer, Cully e Staudt em 1973. Goi (2009) relata o trabalho de McCarthy para refinar a ideia de Borden e definir o mix de marketing como a combinação de todos os fatores sob o comando do gestor de marketing para satisfazer o público alvo. Ele reagrupou os doze elementos de Borden em quatro elementos. McCarthy e Perreault (2002) defendem a utilidade de reduzir todas as variáveis do mix de marketing para quatro básicas: produto, praça, promoção e preço. Tornando o conceito ainda mais funcional, McCarthy e Perreault (2002) afirmam que é de grande ajuda pensar nessas quatro partes do mix de marketing como os "quatro Ps". Chong (2003 como citado em Goi, 2009) afirma que o mix de marketing, como os 4Ps de McCarthy, é originado do $\mathrm{P}$ de preço, da teoria microeconômica.

Dos muitos esquemas propostos, Van Waterschoot e Van den Bulte (1992), colocam o de McCarthy e Perreault como o único que sobreviveu. Os autores sustentam que o conceito acabou se tornando a "concepção dominante" ou "visão recebida". Eles defendem que por serem uma reprodução forte e fácil de lembrar, de princípios incontestáveis, se tornou o mais citado e mais usado sistema de classificação para o mix de marketing, tanto na literatura quanto na prática de marketing. Como consequência, os 4Ps podem também ser definidos como a classificação tradicional do mix de marketing.

As razões que tornam o mix de marketing um conceito poderoso são, segundo Grönroos (1994, como citado em Goi, 2009), fazer o marketing parecer fácil de lidar, permitir a separação das atividades do marketing das demais atividades da empresa, a delegação das atividades de marketing a um especialista e que os componentes do mix podem mudar a posição competitiva de uma organização.

A grande aceitação do Mix entre marqueteiros, segundo Cowell (1984, como citado em Constantinides, 2006), é o resultado da profunda exposição deste conceito durante os anos de faculdade, já que a maioria dos manuais introdutórios de marketing o adota como o "coração da estrutura". Constantinides (2006) coloca o fato de ser fácil de memorizar e aplicar como um ponto forte do modelo. 
Com uma larga escala de aceitação, não é uma surpresa que os 4Ps, segundo Bennett (1995, como citado em Constantinides, 2006), se tornaram sinônimo do termo Marketing, conforme formulado pela Associação Americana de Marketing. Las Casas (1987) traz a definição da AMA, que diz que o marketing consiste no planejamento das quatro variáveis do composto de marketing.

O planejamento do mix de marketing, segundo Kotler e Keller (2006), começa com a formação de uma oferta para satisfazer as necessidades e desejos do cliente-alvo. Esta oferta será julgada pelo cliente pelas, entre outros fatores, características e qualidade do produto. Las Casas (1987) está alinhado com este conceito ao afirmar que o produto é a parte mais importante do composto de marketing.

Las Casas (1987) define produto como sendo o objeto principal das relações de troca que podem ser oferecidos num mercado para pessoas físicas ou jurídicas, visando proporcionar satisfação a quem os adquire ou consome. Kotler e Keller (2006) desmistificam o fato de o produto ser percebido apenas como uma oferta tangível e explicam o produto como tudo o que pode ser oferecido a um mercado para satisfazer desejo ou necessidade. Listam bens físicos, serviços, experiências, eventos, pessoas, lugares, propriedades, organizações, informações e ideias como exemplos de produtos comercializados.

Os produtos somente serão vendáveis, segundo Las Casas (1987) se tiverem benefícios suficientes para motivar o consumidor a comprar. Quanto mais benefícios, maior é a chance de o produto ser escolhido entre as ofertas do mercado. A definição dos benefícios a serem oferecidos dependerá muito das expectativas dos clientes e ofertas da concorrência no mercado de atuação deste produto.

No âmbito do produto são explorados seus níveis, classificação, meios de diferenciação e relação entre marca e produto. Explora-se ainda, dentro do elemento produto no mix, a embalagem, rótulo e garantia do produto. Este conjunto de variáveis, dentre outras, vai compor a política de posicionamento do produto.

O preço, outro componente do mix de marketing, é definido por Las Casas (1987) como o meio de troca do consumidor para adquirir um produto com a empresa que teve um esforço alocado em recursos, capital, mão de obra e manufatura.

Um dos critérios de decisão de compra é o preço dos produtos. Las Casas (1987) aponta que a maioria dos consumidores possuem desejos ilimitados e recursos limitados. Portanto, a alocação eficiente destes recursos otimizará a satisfação dos indivíduos. A relação existente entre a necessidade do comprador e o preço do produto é que, de modo geral, o cliente só comprará o produto ou serviço se o preço justificar o nível de satisfação que virá de sua compra.

Dentro do mix de marketing, Kotler e Keller (2006) colocam o preço como o único elemento que gera receita, enquanto os outros três produzem custos. Ainda o comparando com os outros elementos, o preço é um dos mais flexíveis, já que pode ser alterado com rapidez, ao contrário das promoções, compromissos com canal de distribuição e características dos produtos. O preço é, também, uma forma de informar o posicionamento de valor de um produto ou marca pretendido por uma empresa no mercado.

Las Casas (1987) elenca cinco objetivos para determinação de preços como os mais comuns: retorno no investimento, objetivo de concorrência, preços promocionais, fatia de mercado e fluxo de caixa. Outros objetivos podem ser praticados por organizações públicas ou sem fins lucrativos para determinar seu preço. Kotler e Keller (2006) ressaltam que independendo do objetivo específico, empresas que usam o preço como ferramenta estratégica 
lucrarão mais do que aquelas que deixam seus preços serem estabelecidos pelos custos ou mercado.

A decisão de preço precisa ser, conforme ressalta Hutt e Speh (1998), congruente com os objetivos de marketing e estes precisam estar alinhados com os objetivos gerais da organização. Esta coerência e hierarquia de prioridade deve ser mantida ao se determinar uma estratégia de preço.

Uma organização precisa considerar alguns fatores para estabelecer sua política de determinação de preço. Kotler e Keller (2006) descrevem este processo em seis passos que começam na seleção do objetivo da determinação de preço. Os outros cinco passos são a determinação da demanda, estimativa de custos, análise dos custos, preços e oferta de concorrente, seleção de um método de determinação de preço e seleção do preço final.

Las Casas (1987) elenca fatores que influenciam nas variáveis incontroláveis dos preços, mas que devem ser levados em consideração. O primeiro é a concorrência, mas o autor lista também o estágio de ciclo de vida do produto, fatores culturais e sociais, aspectos políticos, legais e econômicos.

Apenas um bom produto e um preço coerente não são suficientes para garantir sucesso. Las Casas (1987) aponta que é necessário também levar, de uma forma eficiente, este produto até o comprador final, caso contrário, o plano de marketing será deficiente. Dentro do composto de marketing a praça é que engloba estas atividades e estratégias.

A maioria dos fabricantes não vendem direto para seus consumidores finais, conforme afirmam Kotler e Keller (2006), e entre estes dois extemos existem vários intermediários. Estes agentes constituem o canal de marketing, também conhecido como canal comercial ou canal de distribuição. Rosenbloom (2014) afirma que um canal de marketing é uma rede de organizações que fornece utilidades de lugar, tempo e posse aos usuários corporativos ou aos consumidores individuais.

Hutt e Speh (1998) definem o canal de distribuição como a ponte entre o gestor de marketing e o mercado e ressaltam que planejar e gerir este canal é uma tarefa desafiante e constante. $\mathrm{O}$ gestor precisa assegurar que este canal esteja alinhado com as necessidades do seu público alvo. Ao mesmo tempo, é necessário satisfazer as necessidades dos integrantes da cadeia, que desempenham um papel essencial para o sucesso da estratégia de marketing. Rosenbloom (2014) reforça que os canais de marketing chegam a desempenhar um papel essencial nos esforços de competição no mercado por parte das organizações. A importância dos canais é percebida ao ser colocada como um dos nove componentes do modelo de negócio (Osterwalder, Pigneur \& Clark, 2010).

As tarefas desempenhadas pelo canal de marketing são elencadas por Hutt e Speh (1998) como fazer contato com clientes potenciais, negociar, contatar, transferir títulos, comunicar, fazer negociações financeiras, serviços relacionados ao produto, transporte e armazenagem. Kotler e Keller (2006) destacam o papel de converter clientes potenciais em pedidos lucrativos como dos principais papéis e afirmam que é ir além de apenas servir mercados, mas é também criar mercados.

Las Casas (1987) elenca vantagens como racionalização de operações e redução de custos como vantagens do uso de intermediários. É possível se obter economia de escala com a especialização na prestação de certos serviços pelo intermediário. O intermediário assume papeis como gerenciamento de estoque nos pontos de venda, financiamentos para consumidores e vendas que são atividades fora da produção, que é a principal do produtor. Isso geraria custos adicionais. 
Kotler e Keller (2006) ressaltam a importância dos canais de marketing, já que os canais escolhidos afetam todas as outras decisões de marketing. Decisões de preço, força de vendas e propaganda estão diretamente ligadas ao canal. Alguns passos são necessários antes de tomar a decisão final sobre um plano de canal de marketing. Para projetar o canal é necessário analisar as necessidades do cliente, estabelecer os objetivos do canal, identificar as alternativas e avaliar as principais opções de canal (Rosenbloom, 2014).

No contexto brasileiro, Lacerda e Mendonça (2010) destacam estudos na relação entre as organizações e os consumidores (B2C). Tal ênfase gera uma carência de um olhar mais estratégico dos canais desenvolvidos no comércio entre organizações (B2B). Percebe-se que a construção de uma vantagem competitiva para o negócio pode surgir nos dois tipos de canais de marketing, verificando os principais aspectos de cada uma das estratégias (Larentis, \& Slongo, 2008; Demo, Watanabe, Chauvet, \& Rozzett, 2017). Neste ponto, visualiza-se que há uma incorporação do foco da estratégica $B 2 C$ dentro do canal $B 2 B$, ao invés de uma migração de estratégia, de $B 2 B$ para $B 2 C$.Ao usar intermediários, a empresa deve decidir a estratégia que irá usar. Kotler e Keller (2006) destacam a estratégia de push (pressão) e pull (atração). $\mathrm{Na}$ primeira a equipe de vendas e promoção é dirigida ao revendedor para induzir os intermediários a expor, promover e vender o produto aos usuários finais. Já na de pull, a ação do fabricante é direcionada ao consumidor, utilizando propaganda e promoção para induzi-lo a pedir os produtos dos intermediários.

A promoção, com significado de comunicação, é outra variável controlável do composto mercadológico (Las Casas, 1987). Hutt e Speh (1998) destacam a comunicação com clientes existentes e potenciais como uma peça vital para o sucesso do negócio. Afirmam ainda que a experiência já ensinou aos gestores de marketing que nem mesmo o melhor dos produtos de vende sozinho. Os benefícios, soluções e custo efetividade deste produto devem ser comunicados eficientemente para todos os indivíduos que tem alguma influência na compra. Kotler e Keller (2006) vão ao encontro afirmando que no marketing moderno é preciso mais que apenas um bom produto, a um preço atraente e acessível ao cliente. As empresas precisam também se comunicar.

Kotler e Keller (2006) afirmam que, para a maioria das empresas, o maior problema não é comunicar e sim o que dizer, como dizer, para quem dizer e com que frequência dizer.

A comunicação de marketing é definida como "o meio pelo qual as empresas buscam informar, persuadir e lembrar os consumidores - direta ou indiretamente - sobre os produtos e marcas que comercializam" (Kotler, \& Keller, 2006, p. 532). A comunicação de marketing permite, ainda segundo Kotler e Keller (2006), às empresas conectar seus produtos ou marca a outras pessoas, lugares, eventos, marcas, experiências, sensações e objetos. Assim a marca cria uma imagem e se posiciona na memória e contribui para a formação do brand equity.

A propaganda é o elemento central e mais conhecido em um programa de comunicação de marketing, porém não é o único na construção do brand equity (Kotler< \& Keller, 2006). O mix de comunicação de marketing é composto por seis formas essenciais de comunicação. São elas a propaganda, promoção em vendas, eventos e experiências, relações públicas e assessoria de imprensa, marketing direto e vendas pessoais.

O modelo 4Ps de mix de marketing tem uma grande difusão e popularidade, tanto para profissionais quanto para acadêmicos. Sua importância também é reconhecida por vários autores. O modelo chega a ser comparado a Pedra de Roseta da educação de marketing por Lauterborn (1990. como citado em Constantinides, 2006) e é colocado como sinônimo do termo Marketing por Bennett (1995, como citado em Constantinides, 2006). Mesmo toda esta aceitação não ausenta o modelo de críticas. 
Durante as últimas décadas do século XX, houve influências culturais, sociais, demográficas, políticas e econômicas que, combinadas com o rápido avanço da tecnologia, transformaram radicalmente a natureza, o comportamento e as necessidades dos consumidores (Constantinides, 2006). A crescente pressão nas empresas para melhor identificar e satisfazer as mudanças constantes de necessidades dos consumidores, a relevância que os serviços vêm tomando e a necessidade de criação de relações de longo prazo tem contribuído para expor várias limitações do modelo 4Ps como uma ferramenta de gestão de marketing.

Van Waterschoot e Van den Bulte (1992) afirmam que, surpreendentemente, a literatura não entrou em acordo quanto a exatamente mistura de que elementos é o mix de marketing. Eles afirmam que alguns autores mais antigos como Borden (1964), Frey (1956) e Staudt e Taylor (1965) classificam estes elementos como procedimentos, políticas e processos. Por outro lado, a maioria dos autores atuais categorizam estes elementos como parâmetros, ferramentas e instrumentos.

Constantinides (2006) elenca três focos de crítica: como a orientação voltada para a empresa, falta de interatividade com o consumidor e falta de elementos estratégicos. Uma outra revisão destaca as três principais falhas do modelo como sendo as propriedades ou características que são a base da classificação não foram bem identificadas, as categorias não são mutuamente excludentes e algumas subcategorias estão agrupadas quando não deveriam devido a sua importância (Van Waterschoot, \& Van den Bulte, 1992).

Estas críticas são ratificadas por Popovic (2006) que afirma que o modelo é uma definição de marketing orientado a produção e não ao consumidor e Lauterborn (1990) que coloca o modelo com uma perspectiva apenas do gestor de marketing e reivindica que cada uma das variáveis deveria ser vista também pela perspectiva do consumidor.

Apesar do histórico e status do mix de marketing como principal parâmetro teórico e prático do marketing moderno, Constantinides (2006) afirma que vários acadêmicos têm expressado dúvidas e objeções quanto ao valor e o futuro do modelo, propondo alternativas que vão de pequenas mudanças a total rejeição. Constantinides (2006), afirma que, em sua revisão, a maioria dos autores propõem modelos alternativos, enquanto os que estão dispostos a aceitar o modelo 4Ps propõem versões modificadas com novos elementos.

Um número considerável de novos modelos proposta tenta sanar o problema da falta de orientação e interação com o consumidor. Bennett (1997) elenca o modelo proposto por Robins, em 1991, que oferece o 4Cs como alternativa: Consumidores (que compram os bens), Competidores (que oferecem uma alternativa de produto) e capacidades e corporação (ambas se referem a organização que tem a habilidade de satisfazer as necessidades) e a proposta de Ohmae, de 1982, que sugere o 3Cs, modelo com um triângulo de consumidores, competidores e corporação. O modelo é interativo e destaca o relacionamento estratégico e interativo entre as três partes. Bennett (1997) cita ainda a sugestão de Booms e Bitner, de 1981, que sugerem adaptações no modelo atual. A sugestão é acréscimo das esferas pessoas, processos e evidências físicas ao 4Ps tradicionais.

Constantinides (2006) cita outros modelos teóricos, além das propostas já mencionadas: Kotler (1984) que sugere a adição de mais dois Ps (Poder político e formulação da opinião pública), Doyle (1994) que sugere adicionar serviços e equipe, Bennett (1997) que sugere um modelo com 5Vs de valor, viabilidade, variedade, volume e virtude, Vignalli e Davies (1994) e Schultz (2001) que sugerem modelos e técnicas novas e Yudelson (1999) que associa o produto a atividade de performance, o preço a penalidade, a promoção a percepção e a praça e processo. 


\section{Metodologia}

Desde que o objetivo do estudo é analisar a implementação e o resultado da incorporação de uma estratégia de B2C ao B2B, o estudo de caso é a estratégia que melhor atende este propósito. Define-se como único, já que explora apenas um fenômeno. Sobre a unidade de análise, classifica-se como incorporado, já que são múltiplas unidades (Gil, 2002; Yin, 1994). O estudo foi realizado na Coloplast do Brasil, uma subsidiária da homônima dinamarquesa de dispositivos médicos, dentro da divisão de curativos avançados. O fenômeno abordado é a implementação de uma estratégia de abordagem direta ao cliente. A importância do caso ocorre, principalmente, pelo fato que esta unidade de negócio tem o B2B como canal único. Por isso esta estratégia é proposta como um meio de diferenciação. A ação transcende a simples mudança de canal e aborda também estratégia de comunicação e preço. Desta forma, o objeto da pesquisa está alinhado com a pesquisa bibliográfica sobre o Marketing Mix e Estratégia de Canal.

Os dados são primários e foram coletadas em três fontes de evidências: 1) Documentação, por meio dos planos estratégico e operacional; 2) Registros em arquivos, com as metas e o realizado de vendas e; 3) Entrevistas espontâneas, sem obedecer um roteiro fixo. As entrevistas foram feitas pessoalmente e individualmente. Colaboradores da empresa que participaram do processo direta ou indiretamente foram entrevistados, conforme Quadro 1.

\section{Quadro 1 - Informações sobre os entrevistados.}

\begin{tabular}{|l|l|c|c|}
\hline \multicolumn{1}{|c|}{ Cargo } & Gênero & Tempo na empresa \\
\hline 1 & Diretor da Unidade & Masculino & 4 anos \\
\hline 2 & Gerente Regional de Vendas Privado & Masculino & 3 anos \\
\hline 3 & Gerente Regional de Vendas de São Paulo & Masculino & 16 anos \\
\hline 4 & Gerente de Marketing & Masculino & 14 anos \\
\hline
\end{tabular}

Fonte: Elaborado pelos autores.

A escolha dos entrevistados pode ser justificada: 1) Diretor da Unidade, que identificou a oportunidade e incentivou a mudança de estratégia; 2) Gerente Regional de Vendas Privado, que executou o plano e Gerente de Marketing que deu suporte a ação; 3) Gerente Regional de Vendas de São Paulo, que não participou da ação, mas contribui com informações sobre o histórico da empresa no Brasil; e 4) Gerente de Marketing, que suportou a nova estratégia. Como os sujeitos participaram momentos diferentes da implementação, as entrevistas não tiveram roteiro prévio e foram documentadas por escrito. Elas tiveram duração média de 20 minutos e ocorreram durante o mês de junho de 2016. O uso dos trechos no trabalho está relacionado à contribuição ao do fluxo lógico e cronológico de implementação do projeto piloto.

Para analisar os dados, utilizou-se uma estratégia híbrida. Para o primeiro objetivo específico, que é explorar a implementação do modelo, desenvolveu-se uma descrição de caso. Yin (1994) define esta estratégia analítica como o aprimoramento de uma estrutura descritiva a fim de organizar o estudo de caso. O segundo objetivo é avaliar a efetividade do modelo e para este a estratégia foi o confrontamento com as proposições teóricas. A validação dos resultados foi baseada no atingimento ou não dos objetivos propostos pelo projeto piloto, crescimento percentual das famílias de produtos. As análises também usam a Análise Vertical dos indicadores, mensurando a participação percentual de cada item no montante.

Campomar (1991) afirma que há preconceito no uso de estudos de caso em pesquisa e um dos motivos é por se acreditar que somente é verdadeiro o que se pode ser quantificado. Para validar a proposição do segundo objetivo específico, mensurou-se o êxito mediante a 
comparação das vendas com a meta proposta e vendas atual comparadas as vendas antes da implementação da nova estratégia.

\section{Análise e Discussão dos Resultados}

A mudança de visão dentro da empresa resultou na criação de uma estratégia para atingir este público de maneira diferente. A ideia principal é sair da relação onde o profissional de saúde é o foco, caracterizando assim $o B 2 B$, para uma relação onde o consumidor final esteja no centro, migrando assim para algo mais próximo ao $B 2 C$. Percebese, portanto, num novo posicionamento do modelo de negócios, tendo um destaque no componente de canais apoiando-se em Osterwalder, Pigneur e Clark (2010).

Esta estratégia torna-se concreta, neste primeiro momento, por meio da criação de um projeto piloto dentro de uma regional de venda. A implementação e desdobramento da estratégia é o objeto de estudo deste caso, onde explora-se o desenvolvimento e resultados alcançados pela estratégia.

O planejamento da estratégia pelo produto é o ponto de partida empírico. A unidade de produtos de curativos e tratamento de pele possui, atualmente, em seu portfólio, 48 Stock Keeping Units (SKUs). Os produtos são de alta tecnologia e alguns contêm princípios ativos como prata ou ibuprofeno. Uma quantidade considerável destes produtos são para feridas complexas e necessitam de conhecimento de estomaterapia de um profissional de saúde. Porém, uma parte do portfólio é voltado para a fase final da cicatrização, para prevenção ou cuidados com a pele. A primeira premissa foi, portanto, focar nos produtos que tivessem essa finalidade.

Para ratificar esta premissa, foram analisadas as vendas do ano fiscal 2011/12, em quantidade de produtos vendidos, no canal varejo e por família de produtos. O ano fiscal de 2011/12 (o ano fiscal da empresa vai de outubro a setembro, por isso engloba dois anos do calendário) foi escolhido para esta análise por ser o ano anterior a implementação, onde haveria a disponibilidade de dados mais atuais e que retratam melhor o cenário. A Tabela 1 mostra a análise vertical da participação de cada família de produto em relação às vendas totais.

Tabela 1 - Análise vertical das vendas no varejo.

\begin{tabular}{|c|c|c|}
\hline Família & Quantidade & AV (\%) \\
\hline Comfeel & 19.512 & 47,2 \\
\hline Seasorb & 9.980 & 24,1 \\
\hline Purilon & 9.500 & 23,0 \\
\hline Biatain & 2.210 & 5,3 \\
\hline WC Other & 168 & 0,4 \\
\hline
\end{tabular}

Fonte: Base de dados da Coloplast.

Ficou claro aqui que quase metade das vendas é da família Comfeel, que engloba cremes e curativos hidrocolóides. O nome desta família quer passar a ideia de sensação de conforto e vem das palavras Comfort e Feeling da língua inglesa. Este tipo de curativo é usado na fase final da cicatrização e para prevenção, confirmando assim a suposição inicial.

Esta família possui 15 produtos, o que ainda não traria um foco ideal para esta estratégia. $\mathrm{O}$ gerente a frente da regional de vendas afirma, em entrevista, que "foi necessário pensar primeiro no consumidor final. Quais as necessidades das pessoas que queremos atingir e quais produtos podemos oferecer para estas necessidades". Ao alinhar as necessidades e 
soluções que a empresa poderia ofertar, escolheu-se para o trabalho dois produtos, o Comfeel Plus Transparente e o Comfeel Creme Barreira.

O primeiro passo foi a escolha de quais produtos seriam ofertados. Mais uma vez, e de maneira empírica, as decisões tomadas estão alinhadas com os autores estudados para a elaboração deste trabalho. Kotler e Keller (2006) identificam a formação de uma oferta para satisfazer as necessidades de desejos do cliente-alvo como o primeiro passo do planejamento do mix de marketing.

O que a empresa classifica como família de produto é, na verdade, pela classificação de hierarquia de produto de Kotler e Keller (2006), linha de produto. Comfeel seria a linha de produto, Comfeel Plus Transparente e Comfeel Creme Barreira seriam os tipos de produtos, e suas apresentações seriam o nível mais baixo da hierarquia, os itens.

A classificação do nível de produto se torna interessante ao mudar o canal e público alvo destes produtos. Estes produtos, em suas condições originais, que seria a oferta em ambiente hospitalar e para profissionais de saúde, seria classificado como produto ampliado, por suas características e benefícios que os diferenciam da concorrência. Porém, ao trazer esta oferta para a nova estratégia, eles se tornam produtos potenciais por se tratar de uma inovação total, se comparados com as ofertas existentes. Ainda sobre a classificação dos produtos escolhidos, são bens de consumo e, levando em conta durabilidade e tangibilidade, ambos são bens não duráveis visto que vão ser usados poucas vezes.

De uma maneira geral, a abordagem desta nova estratégia, na esfera de produto, foi sair de um grande leque de produtos voltado para profissionais de saúde para uma oferta reduzida, mas que vai de encontro as reais necessidades do novo público alvo.

No que se refere ao preço, a venda para varejo e farmácia somava, no ano fiscal 2011/12, apenas 4,5\% do total, conforme Tabela 2. A baixa representatividade deste canal justifica a ausência de uma política de preço customizada.

Tabela 2 - Distribuição das vendas por canal em 2011/12.

\begin{tabular}{|l|r|r|}
\hline \multicolumn{1}{|c|}{ CANAL } & Venda Líquida (R\$) & AV (\%) \\
\hline DISTRIBUIDOR & $7.832 .636,73$ & 58,6 \\
\hline SECRETARIA / PREFEITURA & $3.090 .472,82$ & 23,1 \\
\hline HOSPITAL PÚBLICO & $1.331 .094,61$ & 10,0 \\
\hline VAREJO & $588.828,03$ & 4,4 \\
\hline HOSPITAL PRIVADO & $215.755,80$ & 1,6 \\
\hline CLÍNICA / CENTRO MÉDICO & $136.279,34$ & 1,0 \\
\hline PLANO DE SAÚDE & $120.836,59$ & 0,9 \\
\hline CENTRO DE REABILITAÇÃO & $37.403,82$ & 0,3 \\
\hline HOME CARE & $12.126,30$ & 0,1 \\
\hline FARMÁCIA & $6.858,54$ & 0,1 \\
\hline ENFERMARIA / CASA DE REPOUSO & $3.296,55$ & 0,0 \\
\hline
\end{tabular}

Fonte: Base de dados da Coloplast.

O preço médio praticado no varejo era de $\mathrm{R} \$ 22,87$ e na farmácia $\mathrm{R} \$ 28,53$, ambos acima do preço médio de venda do Brasil, que era $\mathrm{R} \$ 21,03$, conforme Tabela 3. Fazendo uma análise do fluxo de materiais, representado na figura 8 , o varejo está uma etapa antes do fim da cadeia, assim como o distribuidor e deveria ter os preços alinhados com este. Porém o varejo tinha, em média, um preço $17 \%$ maior que o distribuidor.

O objetivo de preço estava alinhado com o da estratégia, que era a maximização da participação de mercado. Para a nova formação de preço foi levado em consideração os 
seguintes aspectos: Preço praticado por concorrentes em produtos similares; Preço disposto a ser pago pelos clientes alvo e; Mark-up esperado pelo varejo.

Tabela 3 - Preço médio de venda por canal em 2012/13.

\begin{tabular}{|c|c|}
\hline CANAL & PREÇO MÉDIO (R\$) \\
\hline ENFERMARIA / CASA DE REPOUSO & 43,69 \\
\hline FARMÁCIA & 28,53 \\
\hline SECRETARIA / PREFEITURA & 25,54 \\
\hline CLÍNICA / CENTRO MÉDICO & 24,90 \\
\hline HOME CARE & 24,65 \\
\hline VAREJO & 22,87 \\
\hline HOSPITAL PRIVADO & 20,94 \\
\hline DISTRIBUIDOR & 19,48 \\
\hline CENTRO DE REABILITAÇÃO & 19,27 \\
\hline PLANO DE SAÚDE & 19,14 \\
\hline HOSPITAL PÚBLICO & 18,42 \\
\hline BRASIL & 21,03 \\
\hline
\end{tabular}

Fonte: Base de dados Coloplast.

Com estas informações, foi possível formar um preço que fosse efetivo, por ser atrativo para todas as partes. Respeitando a margem mínima da empresa, atingindo o mark-up estipulado pelo varejo e sendo acessível ao consumidor final (Figura 1).

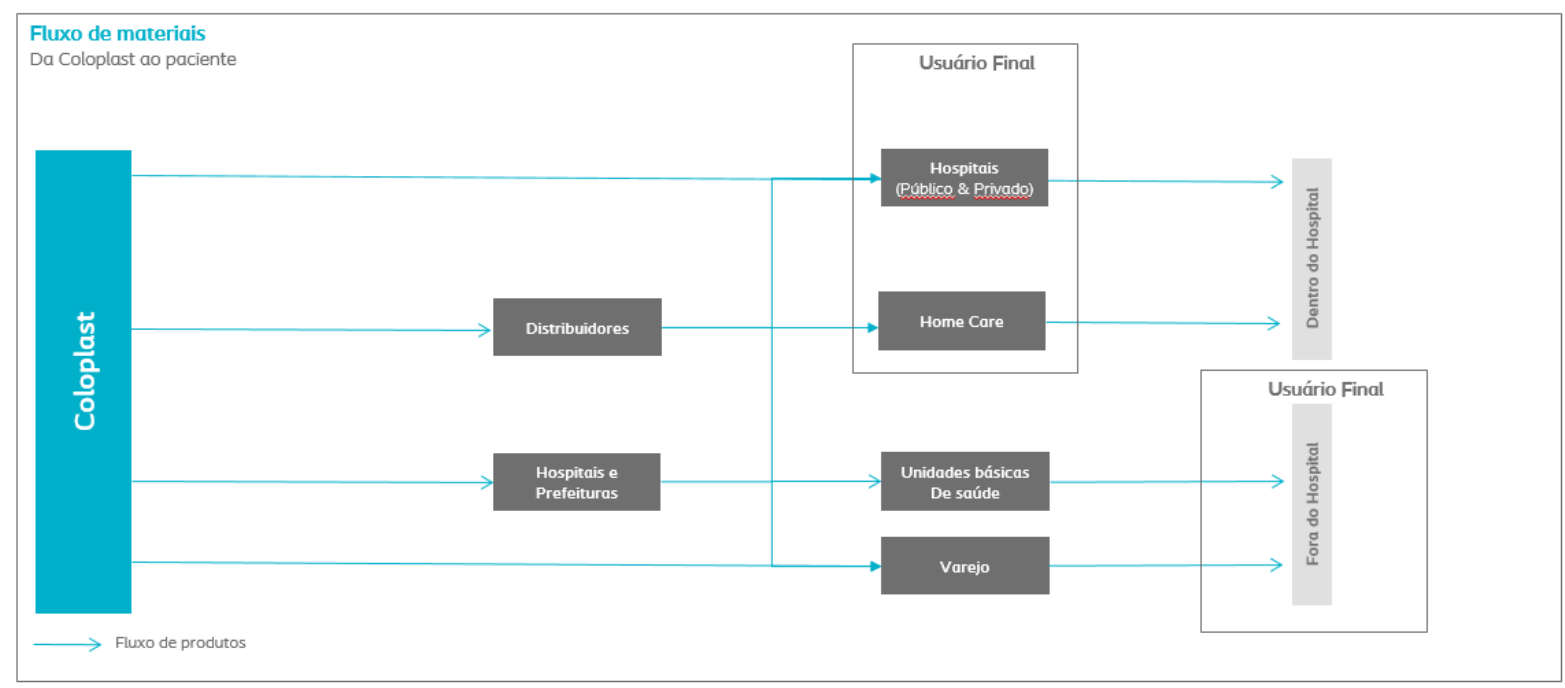

Figura 1 - Fluxo de produtos da Coloplast no Brasil.

Fonte: Base de dados Coloplast.

Durante a construção do plano desta nova estratégia, um stakeholder mapeado não foi contemplado. O balconista foi colocado como peça importante para gerar a demanda destes produtos. Foi criada então uma campanha de incentivo de vendas, onde o balconista levaria um bônus para cada unidade vendida. Este bônus era a última peça que faltava na formação de preço da nova estratégia.

No que tange preço, dentro do mix de marketing, a nova estratégia implementou uma política específica de precificação para este piloto, com o objetivo de maximização da participação de mercado, balizados pelo público alvo e o canal de atuação, elencado por Kotler e Keller (2006). 
O planejamento do canal de distribuição foi um fator crítico de sucesso para essa estratégia. A empresa não tem estrutura física, nem foco para atender diretamente o consumidor final. Quanto mais agentes no canal de marketing, maior será o preço para consumidor final e menor a competitividade. Para ser competitivo no preço, o ideal é optar pelo nível um do canal de marketing, com apenas um intermediário, conforme definem Kotler e Keller (2006).

As opções existentes eram balcão de distribuidor, farmácia e casa cirúrgica. A venda via distribuidor não seria a ideal, já que o cliente final representa pouco para este canal e não haveria foco. A farmácia tem uma grande barreira para o negócio. Alguns produtos não podem ser comercializados aí por serem correlatos ou não terem embalagens individuais.

Como opção de canal, a casa cirúrgica foi escolhida. Ela funciona de maneira semelhante a uma farmácia, mas tem seu foco em produtos médicos, hospitalares e ortopédicos ao invés de medicamentos. A vantagem deste canal é ter o consumidor final como público, ganhando assim no know how de atendimento. Além disso é possível ganhar sinergia com outros produtos, já que é uma casa específica para este tipo de material. O parceiro escolhido para este piloto foi uma casa cirúrgica. A localização na rua Borges Lagoa em São Paulo (SP) (região de concentração de casas cirúrgicas), a relação de alguns anos e abertura para realizar o piloto foram os critérios usados na escolha.

Para a mudança da estratégia, o composto promocional teria que ser modificado também. Um dos aprendizados da linha de produto crônicos foi a necessidade de uma comunicação direcionada e customizada para o consumidor final.

A comunicação original da empresa é totalmente voltada para profissionais de saúde. Há um formato típico do mercado, de uma lâmina dupla de A4, traz informações como composição, descritivo - muito útil para clientes que compram via licitação, indicações, apresentação e código do produto. A linguagem é técnica e pouco condizente com uma interlocução com o consumidor final. Além disso, a imagem utilizada, como pode ser visualizada na Figura 2, remete ao profissional de saúde, visto que o uso está sendo feito com luvas descartáveis. 


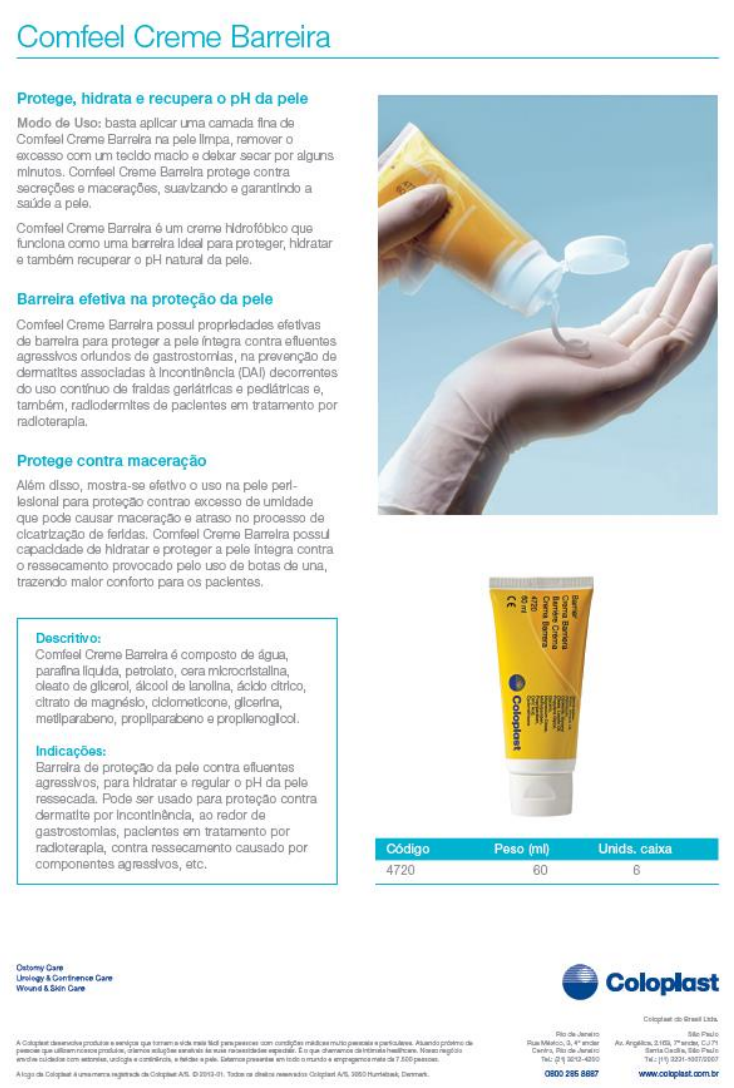

Figura 2 - Lâmina promocional do Comfeel Creme Barreira Fonte: Acervo Coloplast

O gerente de marketing da linha comenta em entrevista que "era necessário mudar toda a comunicação. $\mathrm{O}$ formato, o conteúdo e mensagem. Nada que usamos era apropriado para o consumidor final". A declaração evidencia a inadequação do material ao novo foco, o que comprometeria o efeito desejado para a empresa.

A construção do novo material respeitou as premissas de ser simples e direto, focar na necessidade identificada do nicho alvo e não possuir linguagem técnica. O Creme Barreira tinha uma mensagem demasiada técnica em "Proteção contra maceração, hidratação da pele perilesão e recuperação do $\mathrm{PH}$ da pele". A nova abordagem usaria "Prevenção \& cuidado da pele: a solução completa para assaduras", como mostra a Figura 3. A mensagem ficou clara e direcionada para assadura, necessidade levantada dos clientes.

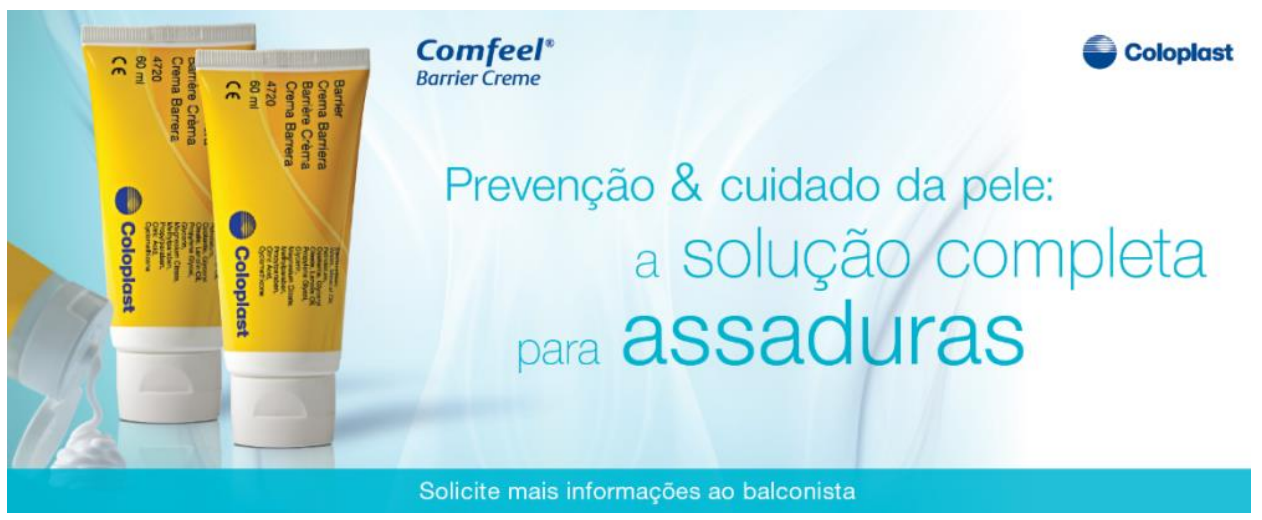

Figura 3 - Nova comunicação do Creme Barreira Fonte: Acervo Coloplast 
Já o Comfeel Plus Transparente, o outro produto foco, tinha seu uso indicado para a fase final da cicatrização e para proteção da pele. A mensagem apresentava palavras técnicas e o principal apelo era o "melhor controle do exsudato". A nova mensagem, exemplificada na Figura 4, foi direta e efetiva: "Proteção garantida. Cicatrização mais rápida".

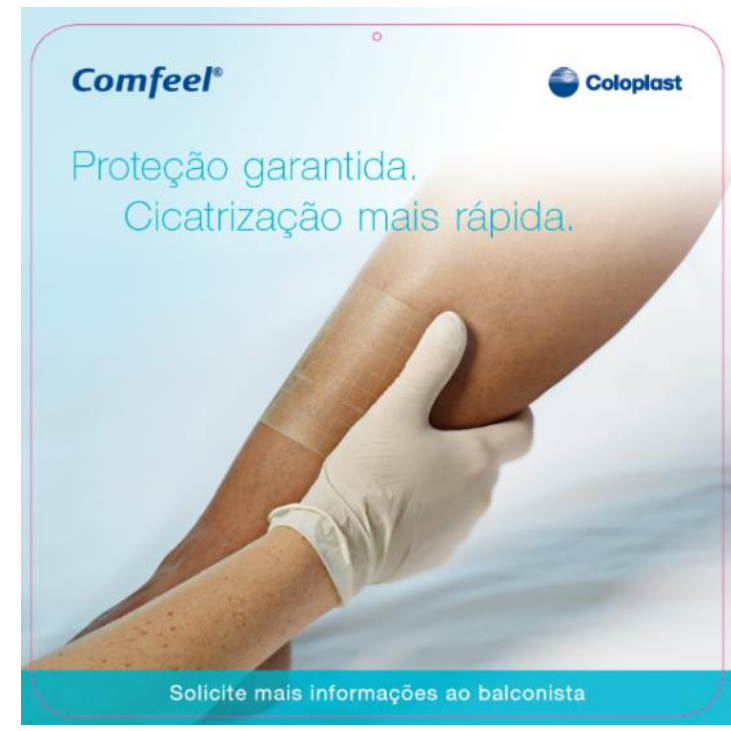

Figura 4 - Mobile do Comfeel Plus Transparente Fonte: Acervo Coloplast

A mensagem estava clara, mas o meio de comunicação também fazia parte da estratégia. Várias peças foram preparadas para compor o ponto de venda, dentre elas mobiles, faixas de gondola, displays, wobblers e stoppers.

Esta primeira etapa engloba a propaganda, uma das seis formas essenciais do mix de comunicação elencado por Kotler e Keller (2006). Uma segunda forma é a venda direta, desempenhada aqui pelo balconista. A importância desta parte torna-se clara quando todos os materiais direcionam os clientes ao balconista.

A terceira forma usada de comunicação usada foi a promoção de vendas. Uma das formas de promoção foi a experimentação e demonstração feita balconistas. A segunda forma está relacionada à sinergia mencionada na escolha da praça. O Creme Barreira é um produto complementar à frauda, por tratar e evitar assaduras. Para todos os clientes que compram fralda é indicado o Creme Barreira pelo balconista ou caixa.

A promoção foi o âmbito do marketing mix que estava mais destoante do almejado para a nova estratégia, por isso foi a que mais consumiu recursos financeiros e humanos. Uma total reformulação do conteúdo, formato e materiais gráficos foi feita para que a mensagem atingisse da melhor maneira o novo público alvo.

Este projeto piloto foi planejado no fim do ano fiscal de 2012/13 e executado no ano fiscal de 2013/14. O planejamento contemplava uma fração de tempo dedicado de um representante de vendas, investimento na criação de novos materiais e amostras. Para justificar o investimento neste projeto piloto e considerar um sucesso, a meta traçada foi de R \$ 40.000 em venda líquida para ano fiscal de 2013/14.

Um outro indicador também foi proposto para mensurar o sucesso do piloto: o crescimento de vendas contra o ano anterior das duas famílias de produto foco. Este projeto foi tratado como prioridade e era revisado trimestralmente pelo time de liderança do Brasil. 
A entrega do projeto foi posta em risco devido à entrega dos materiais e início da nova estratégia. $\mathrm{O}$ projeto que deveria ter começado em outubro (primeiro mês do ano fiscal da empresa) atrasou para dezembro.

Alguns aprendizados e ajustes no plano inicial foram essenciais para a execução. Apresentação dos produtos aos balconistas e reciclagem de treinamentos não tinham sido comtemplados. A premiação inicialmente estipulada para os balconistas não estava alinhada com a prática de mercado e teve que ser reajustada. O layout no ponto de vendas teve que ser negociado posteriormente para que o produto ficasse próximo as fraldas para ganhar sinergia. Por fim, o cadastro dos clientes que compram fralda e a oferta ativa do produto foi essencial para o aumento das vendas.

Tabela 4 - Evolução de vendas Comfeel e Creme Barreira na Cirúrgica.

\begin{tabular}{|l|c|r|r|}
\hline \multicolumn{1}{|c|}{ Família } & $\mathbf{2 0 1 2} / \mathbf{1 3}$ & $\mathbf{2 0 1 3 / 1 4}$ & $\mathbf{2 0 1 4 / 1 5}$ \\
\hline Comfeel & $\mathrm{R} \$ 6.305,00$ & $\mathrm{R} \$ 13.363,00$ & $\mathrm{R} \$ 21.805,00$ \\
\hline Creme Barreira & $\mathrm{R} \$ 3.156,00$ & $\mathrm{R} \$ 4.823,00$ & $\mathrm{R} \$ 6.776,00$ \\
\hline
\end{tabular}

Fonte: Base de dados da Coloplast

O projeto atingiu seu objetivo inicial, já que ao fim do ano fiscal 2013/14 a linha Cirúrgica somou R\$ 46.805 em vendas líquidas, superando em 17\% a meta estipulada. Quanto a mensurável qualitativa, que era o crescimento dos produtos foco, também foi satisfatória. O resultado mostrou que os produtos foram bem escolhidos e que a adaptação da comunicação foi bem executada. O Comfeel Plus Transparente teve um crescimento de $112 \%$ no primeiro ano e $63 \%$ no segundo. Já o Creme Barreira cresceu 53\% no primeiro e $41 \%$ no segundo ano, conforme a Tabela 4. A nova estratégia do composto de marketing, voltada ao consumidor final, se mostrou eficiente ao atingir os objetivos propostos, mesmo com início do projeto dois meses após o planejado.

\section{Considerações Finais}

A proposição deste trabalho foi analisar o modelo de negócios por meio da implementação de uma estratégia que foca no consumidor final em modelo já existente de $B 2 B$, a partir do estudo de caso na empresa Coloplast S.A. A unidade de negócio analisada tem atuação predominantemente na estratégia de canal B2B, vendendo para instituições de saúde e colocando o profissional de saúde como seu cliente final. Com a identificação de uma tendência e forma de diferenciação, decidiu implementar uma estratégia focada no consumidor final, aproximando-se, assim, do modelo B2C.

Um dos objetivos específicos era investigar a implementação desta estratégia, comparando com a estratégia anterior e analisando sempre na moldura dos 4Ps de marketing e nas estratégias de canais. O outro objetivo específico era avaliar o resultado e efetividade deste novo modelo.

O primeiro objetivo foi alcançado ao descrever, além da implementação da estratégia, o seu planejamento. As estratégias de canais antes e depois foram comparadas, sempre estruturadas dentro dos 4Ps do mix de marketing. Desta forma, foi realizada a ligação com o referencial teórico, em classificações, objetivos e passos de cada uma das partes do mix.

O segundo objetivo avaliou o sucesso do projeto piloto pelas mensuráveis escolhidas durante o planejamento. A estratégia alcançou seu objetivo ao atingir a meta estabelecida e mostrar um crescimento significativo nos produtos alvo. 
Um fato crítico para o estudo de caso foi o acesso as informações. Os arquivos e números cedidos pela empresa e pela casa cirúrgica, além das entrevistas realizadas, foram essenciais para o desenvolvimento do estudo. Já como limitações da pesquisa, pode-se citar que o tempo e a investigação de uma empresa ainda são limitados para se ter um resultado concreto. Apesar de a implementação desta estratégia ter atingido os objetivos propostos, para validá-la seria necessário mais tempo de análise para confirmar o resultado como sustentável e a realização em mais de uma empresa. Por outro lado, é importante visualizar um direcionamento dos resultados para que alterações na estratégia de canal possam agregar mais valor ao modelo de negócios conforme observado por Kotler e Keller (2006), Osterwalder, Pigneur e Clark (2010) e Rosenbloom (2014).

Sendo assim, pode-se afirmar que a estratégia implementada atingiu os objetivos propostos para o projeto piloto, porém ainda não é possível generalizar essa tendência como realidade no Brasil. Além disso, não é possível constatar que essa estratégia funcione para qualquer empresa ou que seja um meio de diferenciação dentro deste mercado.

O mercado de dispositivos médicos no Brasil ainda não é totalmente auditado e essa assimetria de informação resulta em muitos fatores para a ineficiência deste ramo. Como recomendações de estudos futuros, é interessante o desenvolvimento de estudos sobre as margens de lucro e eficiência em cada uma das etapas da cadeia de suprimento, aceitação de canais de venda eletrônicos, sistema de remuneração de plano de saúde e consequências da judicialização no sistema de saúde. $\mathrm{O}$ aprofundamento destes temas poderia complementar o presente trabalho e oferecer benefícios para o sistema de saúde, visto que busca analisar a eficiência da cadeia e, por consequência, possibilidades de maior acesso para o usuário final.

\section{REFERÊNCIAS}

Andersen, P. H. (2005). Relationship marketing and brand involvement of professionals through web-enhanced brand communities: The case of Coloplast. Industrial marketing management, 34 (1), 39-51.

Baker, M., Saren, M. (2010). Marketing Theory: a student text. 2. Ed. Londres: Sage.

Bennett, A. R. (1997). The Five Vs - A Buyer's Perspective of the Marketing Mix. Marketing Intelligence \& Planning, 15 (3), 151-156.

Borden, N. H. (1984). The Concept of Marketing Mix. Journal of Advertising Research. Classics, 2, September, 7-13.

Campomar, M. C. (1991). Do uso de "estudo de caso" em pesquisas para dissertações e teses em administração. Revista de Administração. 26 (3), 95-97.

Coloplast S. A. (2015). Let's talk magazine. Humlebaek: Coloplast S.A.

Constantinides, E. (2006). The Marketing Mix Revisited: towards the 21st century marketing. Journal of Marketing Management, 22 (3/4), 407-438.

Demo, G., Watanabe, E. A. M., Chauvet, D. C. V., \& Rozzett, K. (2017). Customer relationship management scale for the B2C market: a cross-cultural comparison, Mackenzie, Management Review - Revista de Administração da Mackenzie, 18 (3), may./ jun. 42-69 
Dhabuwala, C., Sheth, S., Zamzow, B. (2011). Infection rates of rifampin/gentamicin-coated Titan Coloplast penile implants. Comparison with Inhibizone-impregnated AMS penile implants. The Journal of Sexual Medicine, 8 (1), 315-320.

Dickson, P. R., Farris, P. W., Verbeke, W. J. (2001). Dynamic strategic thinking. Journal of the Academy of Marketing Science, 29 (3), 216-237.

Gil, A. C. (2002). Como elaborar projetos de pesquisa. 4a . São Paulo: Atlas.

Goi, C. L. (2009). A Review of Marketing Mix: 4 Ps or More? International Journal of Marketing Studies. 1 (1), 2-15.

Gummesson, E.; Polese, F. (2009). B2B is not an island!. Journal of Business \& Industrial Marketing, 24 (5/6), 337-350.

Hutt, M.; Speh, T. (1998). Business Marketing Management: a strategic view of industrial and organizational markets. 6th. Orlando: Dryden.

Kotler, P. (1998). Administração de marketing: análise, planejamento, implementação e controle. 5 $5^{\text {a }}$ São Paulo: Atlas.

Kotler, P., Keller, K. L. (2006). Administração de marketing. São Paulo: Pearson Prentice.

Lacerda, T. S., Mendonça, B. Q. (2010). Marketing B2B: mapeamento dos trabalhos acadêmicos no Brasil de 1998 a 2007. Revista de Administração da UFSM. 3 (2), mai./ago., 219-229.

Larentis, F., \& Slongo, L. A. (2008). Relacionamento em canais de marketing como forma de vantagem competitiva sustentável: um estudo com fabricantes de móveis e lojas exclusivas. Revista de Administração, 43 (3), jul./ago./set., 200-223.

Las Casas, A. (1987). Marketing: Conceitos, Exercícios e Casos. São Paulo: Atlas.

Lauterborn, B. (1990). New Marketing Litany: Four Ps Passé: C-Words Take Over. Advertising Age, 61(41), 26.

McCarthy, E. J. (1960). Basic marketing: a managerial approach. Homewood, IL: Richard D. Irwin.

McCarthy, E. J., Perreault, W. D. (2002). Basic Marketing: a global managerial approach.14st. New York: McGraw-Hill Irwin.

Nielsen-Englyst, L. (2003). Operations strategy formation-a continuous process. Integrated Manufacturing Systems, 14 (8), 677-685.

Onarheim, B. (2012). Creativity from constraints in engineering design: lessons learned at Coloplast. Journal of Engineering Design, 23 (4), 323-336. 
Osterwalder, A., Pigneur, Y., Clark, T. (2010). Business model generation: a handbook for visionaries, games changers, and challengers. New Jersey: Jon Wiley \& Sons.

Palmer. A. (2004). Introduction to Marketing: theory and practice. 3rd. Oxford: Oxford University Press.

Popovic, D. (2006). Modelling the Marketing of High-Tech Start-Ups. Journal of Targeting, Measurement and Analysis for Marketing, 14(3), 260-276.

Porter, M. E. (1986). Estratégia competitiva: técnicas para análise de indústrias e da concorrência. Rio de Janeiro: Campus.

Rosenbloom, B. (2014). Canais de Marketing: uma visão gerencial. São Paulo: Cengage Learning.

The Economist. (2016). Brazill's fall. The Economist. 2016. Recuperado em 19 fevereiro, 2016, de http://www.economist.com/news/leaders/21684779-disaster-looms-latin-americasbiggest-economy-brazils-fall.

Van Waterschoot, W., Van Den Bulte, C. (1992). The 4P classification of the marketing mix revisited. The Journal of Marketing, 56 (4), 83-93.

Yin, R. K. (1994). Estudo de caso: planejamento e métodos. 2a . Porto Alegre: Bookman. 